\title{
CONHECIMENTOS PRÉVIOS EM OFICINAS DE ROBÓTICA: OBSERVAÇÓES DE UM DIÁRIO DE BORDO
}

\author{
Andréa Cantarelli Morales ${ }^{1}$ \\ Patrícia Giacomelli ${ }^{2}$ \\ Francisco Catelli ${ }^{3}$
}

\begin{abstract}
Resumo: Esse trabalho apresenta as percepçóes de professoras de uma Instituição de Ensino Superior sobre a importância dos conhecimentos prévios na realização de oficinas de robótica educacional. Através de observaçóes realizadas do decorrer das atividades propostas, foram identificadas três categorias de estudantes conforme suas condiçóes prévias, sendo discernido, para cada uma delas, um padrão de comportamento empregado na resolução das tarefas. Essa percepçáo possibilitou a reflexão das professoras acerca da importância do reconhecimento e da utilização dos conhecimentos prévios para a construção do conhecimento por parte dos estudantes. Além disso, o professor pode fazer uso dessas condiçóes prévias para o planejamento de atividades e uma prestação mais adequada de auxílio na realização das mesmas.
\end{abstract}

Palavras-chave: Conhecimentos prévios; Robótica educacional; Diário de bordo.

\section{PREVIOUS KNOWLEDGE IN ROBOTICS WORKSHOPS: OBSERVATIONS FROM A LOGBOOK}

\begin{abstract}
This paper presents the perceptions of teachers from an University Education Institution about the importance of prior knowledge in conducting educational robotics workshops. Through observations made during the proposed activities, three categories of students were identified according to their prior knowledge, being discerned, for each of them, a pattern of behavior employed in the resolution of tasks. This perception allowed the teachers to reflect about the importance
\end{abstract}

1 Docente do curso de Engenharia Elétrica na Universidade de Caxias do Sul. Mestra em Educação e Doutoranda em Educação pela Universidade de Caxias do Sul. Bolsista PROSUC/CAPES Modalidade II.

2 Docente do curso de Engenharia Elétrica na Universidade de Caxias do Sul. Mestra em Engenharia Elétrica.

3 Docente em Física na Universidade de Caxias do Sul. Mestre em Engenharia de Minas, Metalúrgica e de Materiais e Doutor em Educação. 
of recognition and use of prior knowledge for the construction of knowledge by the students. In addition, teachers can make use of these preconditions for planning activities and providing more appropriate assistance in carrying them out.

Keywords: Prior Knowledge; Educacional Robotics; Project diary.

\section{Introduçáo:}

O texto tem por objetivo descrever as anotaçóes realizadas em um diário de bordo de duas professoras universitárias, realizado em oficinas de Robótica Educacional ministradas para estudantes do Ensino Fundamental e Médio. Este diário de bordo foi escrito com a pretensão de relatar todas as observaçóes durante estas oficinas, visando náo somente a questáo cognitiva envolvida durante as oficinas, mas também o envolvimento social e a interação entre os participantes. Outrossim, as observaçóes registradas no diário de bordo foram se potencializando à medida que foram ocorrendo mais oficinas, principalmente envolvendo a questão cognitiva.

Os conceitos de conhecimento prévio, dialogicidade e interação, estão presentes em praticamente todos os registros e servem de conjuntura para as reflexóes tencionadas. $\mathrm{O}$ cognitivismo de David Ausubel serve como suporte para as reflexóes em torno dos conhecimentos prévios; Paulo Freire e outros autores contribuem em especial para os diagnósticos e interpretações despertadas a partir dos registros.

A organizaçáo do texto parte das observaçóes dos registros no diário de bordo em relação às concepçóes cognitivas, apresentando as diferentes aprendizagens e evidenciando os diversos conhecimentos prévios.

\section{Desenvolvimento:}

\section{- Diário de bordo e os conhecimentos prévios:}

Partindo da idealização de duas professoras universitárias, foi desenvolvido um projeto de extensáo ofertando oficinas de Robótica Educacional para estudantes do Ensino Médio e Fundamental a partir do $8^{\circ}$ ano. Estas oficinas eram semestrais e tinham duração de aproximadamente 10 encontros. Para a realização das atividades foram utilizados kits do LEGO $^{\circ}$ Mindstorms da versão RCX, a mais antiga das linhas, lançada no final da década de 90. Essa versão difere das que a sucederam (NXT e EV3, respectivamente) tanto pelas características de seus controladores, sensores e atuadores, mas também pelo tipo de peças disponíveis, as quais, no caso do RCX, se assemelham com as clássicas peças de $\mathrm{LEGO}^{\circ}$, e não com estruturas típicas, usadas nos conjuntos de robótica mais atuais. Nas primeiras oficinas a programação era desenvolvida para o controlador específico e ocorria através do próprio programador LEGO ${ }^{\circ}$. Com o passar dos semestres este foi substituído por controladores Arduino. Fazemos aqui este comentário para a compreensão de que as oficinas não se resumiam somente à montagem de protótipos, porém a programaçáo não será foco de observação relatado no diário de bordo. 
Para a realização das atividades propostas os estudantes eram distribuídos em grupos de no mínimo 2 e no máximo 4 participantes. Essa organização tinha por objetivo dois pontos importantes. Um deles era a formaçáo de grupos com vista a integração dos alunos e a interação entre eles durante as atividades, promovendo o envolvimento social e a construção de conhecimento a partir da troca de experiências e saberes. Esse ponto garantia que nenhum estudante desenvolveria a tarefa sozinho. Outra questão, que determinava a formação de grupos com um maior número de integrantes, era o tamanho da turma por conta da quantidade de peças disponíveis para montagem. É importante, porém, ressaltar que a formação dos grupos não era impositiva, ficando a composiçẫo dos grupos a critério dos próprios alunos.

Estas oficinas de robótica tinham vários objetivos, dentre eles: estimular os participantes interessados a cursar o Ensino Superior na área das Exatas; propiciar a criação de protótipos envolvendo robótica educacional, os quais apresentavam relaçáo com conceitos estudados na escola, em especial, aqueles associados à Mecânica na disciplina de Física; estimular a criatividade e desenvolver habilidades para o trabalho em equipe. Para que alguns desses objetivos fossem alcançados, as propostas das atividades eram apresentadas de forma ampla. Era lançado o desafio da construção de um dado protótipo, com determinadas dimensôes e a especificaçáo da quantidade e tipos de motores e sensores, quando se fazia necessário algum monitoramento e/ou movimentação. Outro elemento que era destacado na proposta estava relacionado com a otimizaçáo de peças. Essa tinha vínculo com o conceito de estruturas trabalhado na disciplina de Física (normalmente na forma de treliças). Neste momento as professoras abriam um espaço para discussão de conceitos interdisciplinares de conteúdos básicos (Morales e Giacomelli, 2019), para que os estudantes pudessem compartilhar suas noçóes e conhecimentos. Desta forma, o modo de construção do protótipo ficava à cargo de cada grupo de trabalho, sendo que cada participante usaria de sua imaginaçáo e criatividade, além de sua percepção para o encaixe das peças.

Já na primeira oferta do curso, que teve início no ano de 2016, as professoras se organizaram para relatar as observaçóes realizadas durante as oficinas em um diário de bordo. Nele eram descritas observaçôes relacionadas à percepção quanto à dificuldade ou facilidade referente à montagem, a inter-relação entre os participantes de cada grupo, quanto ao seu envolvimento com a programaçáo e ainda observaçóes gerais. Com o decorrer dos semestres, os descritos com relação à facilidade ou dificuldade de montagem e a sua relação com os conhecimentos prévios dos participantes foram ficando mais evidentes. Assim se buscou intensificar os descritos sobre estas observaçôes.

Mas relacionar a facilidade ou dificuldade de montagem com os conhecimentos prévios parece ser algo táo trivial, que o leitor deve estar se questionando o porquê de tanta ênfase nesta observação. Para essa justificação, inicialmente enunciaremos nosso conceito de conhecimento prévio, fundamentado em Ausubel (1980): tratase dos conhecimentos já existentes na estrutura cognitiva do sujeito. Assim, para a apropriaçáo de novos conceitos é necessário que estes tenham como âncora os conhecimentos prévios, também chamados pelo autor citado de subsunçores. 
Como as oficinas tinham duração de apenas 30 horas, as professoras não buscavam evidenciar o conhecimento prévio dos estudantes sobre a montagem com peças de LEGO', porém estes conhecimentos foram se revelando à medida que o diálogo com os participantes se intensificava, sendo esses relatados no diário de bordo.

$\mathrm{Na}$ primeira turma tivemos estudantes com dois tipos de condiçôes prévias identificadas: o primeiro diz respeito ao estudante que já teve contato com LEGO na infância, e o segundo tem relaçáo com o estudante que, além de um muito provável contato na infância, já participou, na escola, de atividades com conjuntos de LEGO` voltados à robótica educacional. Essas condições prévias foram identificadas durante as atividades realizadas na oficina, através de questionamentos informais com os participantes e posteriores registros no diário de bordo.

O estudante que já montou LEGO $^{\circ}$ na infância teve uma relação com esta "brincadeira", que evidentemente teve características individuais para cada um. Mas cabe aqui ressaltar que, embora muitos desses brinquedos viessem com instruçóes de montagem, identificando exatamente em qual posição cada peça do brinquedo deveria se encaixar com outra, esse processo não necessariamente ficava limitado. Ou seja, a criança poderia usar de sua imaginação e criar outras possibilidades de estruturas. Por esse motivo pode-se conjecturar que o LEGO` na infância incentiva a criatividade.

Em se tratando das atividades com LEGO $^{\circ}$ ofertadas nas escolas, as professoras precisaram buscar informaçóes por desconhecerem o processo como estes são trabalhados. Nesta pesquisa se identificou que as atividades propostas nas escolas eram de montagem orientada, ou seja, existia um manual de montagem peça por peça e os estudantes não podiam modificar a estrutura de montagem proposta, até que a programação final fosse efetuada. Ou seja, somente no final da atividade é que podiam personalizar o seu protótipo como desejassem. Este processo de trabalho, segundo Freire (1996) desestimula a autonomia além de podar a criatividade. Essas duas formas de condiçôes prévias se repetiram nas duas turmas seguintes.

Em semestre posterior foi realizada uma oficina de curta duração com estudantes de Ensino Fundamental de séries finais de uma escola específica. Esta escola está localizada na periferia do município de Flores da Cunha e, neste momento, se evidenciou um terceiro tipo de condição prévia: aqueles alunos que nunca tiveram contato com LEGO $^{\circ}$, nem mesmo na infância. Tratando-se de uma oficina de curta duração, seus objetivos eram diferentes dos mencionados no caso do curso de extensáo, sendo o principal deles o acolhimento da comunidade, dada a natureza da IES. Ainda assim, buscava-se apresentar aos estudantes a área das Exatas, mostrando que as ciências também podem ser divertidas. Desta forma, a proposta se baseava na construção de um protótipo que deveria realizar um determinado movimento, o qual era definido através da programação do controlador, disponibilizada para os estudantes. Ou seja, excluindo-se a parte do desenvolvimento da programação, a tarefa era a mesma utilizada anteriormente com outras turmas. Mesmo a atividade tendo um período mais reduzido de realização, 
foi possível compilar um número significativo de observaçóes, observaçóes essas que se revestiram de grande importância na construção desta pesquisa.

Até essa fase da pesquisa, tinham sido recolhidas observaçóes somente com estudantes que, de algum modo, já haviam tido contato com o LEGO (os estudantes que tinham tido contato com o LEGO na infância, e os que tinham tido a oportunidade de trabalhar com o LEGO na escola). Nesses casos, embora houvesse dificuldades na elaboração das montagens, a intervenção por parte das professoras era mínima, e os grupos, através de interação entre os participantes, eram capazes de construir $\sigma$ os protótipos solicitados. Porém, na ocasião da oficina de curta duraçáo, com os estudantes que nunca tinham tido contato prévio com o LEGO, ficou evidente a importância e a necessidade de o professor perceber se os estudantes, a partir de suas experiências prévias, tinham mais ou menos facilidade nas montagens; o que permitiria orientar a atividade de uma forma mais direcionada, de acordo com as necessidades de cada grupo. Essa atividade teve início como as demais, sendo apresentado o desafio da construção do protótipo. $\mathrm{Na}$ sequência, diferentemente do que acontecia nas outras turmas, foi indicada a necessidade de uso de motor para a execução do movimento, o qual seria realizado por rodas que deveriam ser conectadas entre si por eixos. Esses elementos foram simplesmente apresentados aos estudantes. Os demais requisitos da montagem eram livres e cada grupo poderia personalizar seu protótipo de acordo com seu desejo. Observou-se que o encaixe das peças clássicas - usadas para a elaboração da base para o controlador e dos atributos de decoração do protótipo - não se apresentou como um problema, uma vez que seu uso é muito intuitivo. Entretanto, o mesmo não aconteceu com a conexão de outros elementos. Um exemplo disso é o fato de muitos grupos elaborarem a montagem da base com as rodas e, posteriormente, simplesmente conectarem o motor em algum local da estrutura, sem relacionar que o eixo desse deve ser, de alguma forma, interligado com o eixo das rodas, para que essas se movimentem.

Em vista disso, a conduta das professoras sofreu alteração, buscando, em um primeiro momento da oficina, identificar os conhecimentos prévios dos participantes das mesmas, podendo ser até mesmo através de uma rápida conversa com o grupo, ou mesmo através de questionários aplicados no início da oficina. Com este novo procedimento, as observaçóes quanto à dificuldade ou facilidade de montagem já tinham subsídios de acordo com os conhecimentos prévios já informados dos participantes das oficinas de robótica e as professoras podiam direcionar de uma forma mais eficiente os conceitos necessários para uma montagem mais eficaz.

\section{- Reflexóes acerca de alguns conhecimentos prévios identificados nos participantes:}

As observações descritas no diário de bordo constituíram-se como um o objeto de amparo pedagógico para a mudança de estratégia metodológica de ensino das professoras que ministram as oficinas de robótica. Segundo Ausubel (1980), para que haja a aquisição de novos conhecimentos é necessário que a nova informação encontre subsídios para ancorar em conhecimentos já existentes na 
estrutura cognitiva do sujeito. Antes destas observaçóes estarem táo presentes na percepção das professoras, elas não buscavam evidenciar o conhecimento prévio dos estudantes, porque elas acreditavam que, como a oficina era de curta duração, não haveria a necessidade desse levantamento, e assim o tempo seria aproveitado integralmente na execução da atividade. Assim, aqueles que já conheciam LEGO realizariam a atividade de forma mais rápida e eficaz e os que náo conheciam tomariam um pouco mais de tempo, mas alcançariam o mesmo resultado.

Porém, essa crença das professoras pesquisadoras se revelou equivocada, a partir das observaçóes aqui relatadas. Essas observaçóes obrigaram as professoras pesquisadoras a reformular seu procedimento usual, transformando-o, e mesmo re-transformando-o. A esse processo Paulo Freire (1979) denomina de comprometimento. Somente o homem é capaz de se comprometer, pois para isso ele precisa ter capacidade de atuar e refletir.

Um aspecto bastante paradoxal merece ser retratado aqui: os participantes que já conheciam LEGO na infância apresentaram inicialmente alguma dificuldade na montagem das estruturas. Isso se deve ao fato de o LEGO ${ }^{\circ}$ clássico, como brinquedo, possuir peças de montagem tradicionais, as quais se encaixam para formar torres ou casas por exemplo. Já as peças do LEGO ${ }^{\circ}$ Mindstorms da versão RCX são utilizadas para a concepção de estruturas mais complexas, podendo-se construir treliças, relaçóes de cremalheira e engrenagens, arranjos com polias e demais montagens necessárias para elaboração de estruturas com possibilidades de movimentação. Mas o fato de os participantes já conhecerem previamente o LEGO parece não ter gerado uma, digamos, habilidade prévia nas montagens. Cabe, porém, destacar que essa dificuldade foi rapidamente sanada com o desenvolvimento de algumas possibilidades de montagem. Este processo de apresentaçáo de possibilidades de montagem pode ser identificado como um processo dialógico (Freire, 1987). Para Freire, o diálogo verdadeiro somente irá ocorrer se o homem tiver um pensar crítico e deve iniciar buscando elementos para o desenvolvimento da atividade proposta. Esse diálogo se faz necessário pois a educação não "é transferida" de um ser para o outro, ela ocorre de uma forma mediada. Por conta do que foi posto acima, é possível inferir que, num primeiro instante, não houve o diálogo. Porém, as reflexões sobre as anotaçóes no diário de bordo fizeram com que as professoras identificassem a necessidade do diálogo como elemento importante para a construçáo da atividade proposta.

Não seriam poucos os exemplos que poderiam ser citados, de planos, de
natureza política ou simplesmente docente, que falharam porque os seus
realizadores partiram de uma visáo pessoal da realidade. Porque náo levaram
em conta, num mínimo instante, os homens em situação a quem se dirigia
seu programa, a não ser com puras incidências de sua açáo (FREIRE, 1987,
pg. 84)

Após as reflexôes acerca dos estudantes que conheciam LEGO ${ }^{\circ}$ na infância, o olhar se voltou para os estudantes que tiveram atividades de LEGO ${ }^{\circ}$ Mindstorms na escola, sendo que também trabalhavam com robótica educacional. Na primeira percepção das professoras, estes seriam os primeiros estudantes a concluir as 
atividades propostas, porém este fato não ocorreu. Conforme anotado no diário de bordo, estes estudantes, que à princípio já possuíam conhecimentos prévios sobre LEGO' montavam e desmontavam várias vezes seus protótipos. Poucas não foram as vezes que as professoras foram oferecer ajuda, ou mesmo pergunta-lhes sobre as estratégias de montagem que eles estavam tentando executar. Nas primeiras aulas estes estudantes forneciam uma desculpa qualquer para continuarem nas suas atividades, e com este gesto, as professoras tinham a impressão de que eles não queriam pedir ajuda. Esta impressão foi reforçada no decorrer das atividades, quando as professoras perguntaram aos participantes se eles já tinham tido contato com LEGO $^{\circ}$. Eles responderam que sim, já tinham trabalhado com LEGO $^{\circ}$ na escola e que inclusive já tinham participado de campeonatos de robótica, deixando até transparecer um certo ar de superioridade. Foi essa resposta dada às professoras pesquisadoras que as levaram a conjeturar que os estudantes não queriam "dar o braço a torcer" e admitir que estavam com dificuldades. Com o passar do tempo, eles foram deixando de lado esse "orgulho" e passaram a solicitar ajuda para executar as montagens.

A respeito dos relatos feitos acima, Moreira \& Masini (2011) com sua teoria da aprendizagem significativa crítica (que consiste numa complementação da teoria da aprendizagem significativa de Ausubel) nos apresentam nove novos princípios que estão voltados aos perfis dos estudantes de hoje, contemplando as tecnologias modernas. Desses nove princípios, ressaltamos três, que parecem dar conta dos relatos feitos até aqui: a) princípio do aprendiz como perceptor/representador: o estudante percebe o mundo e o representa, mas o que importa realmente é o que ele percebe, esta percepção tem relação com o que ele já conhece, além de também ter a influência da linguagem; b) princípio da aprendizagem pelo erro: este princípio está relacionado com a identificação do erro, não devemos confundi com a aprendizagem pelo ensaio e erro, mas sim promover no estudante a identificação do erro, buscando-o sistematicamente e assim motivando os estudantes a aprenderem pela superaçáo; c) princípio da desaprendizagem: Moreira \& Masini apresentam duas razóes para a desaprendizagem, a primeira é que, para haver a aprendizagem significativa, é preciso ancorar o novo conhecimento aos conhecimentos prévios existentes, porém quando os conhecimentos prévios não são adequados é preciso "desaprende-los".

Observando com mais atenção estes princípios refletimos em torno da aprendizagem pelo erro. Um dos objetivos destas oficinas é, sim, a aprendizagem pelo erro, pois como não são determinadas pré-montagens, mas somente são dadas dicas gerais de montagem, os estudantes vão tentar algumas vezes e perceber que certas estruturas acabam sendo melhores que outras, por serem mais reforçadas, utilizarem menor quantidade de peças, ou mesmo por se estruturar melhor na montagem por partes. Além disso, muitas vezes a montagem de uma estrutura não é adequada para um dado projeto, mas em outra oportunidade pode ser utilizada com bons resultados. Porém, esses não são erros propriamente ditos, mas sim possibilidades melhores de incorporação na estrutura. Outra reflexão que se faz é sobre o princípio do estudante como perceptor das suas atividades. Nas observaçóes realizadas, 
percebeu-se que cada estudante constrói os protótipos segundo a sua percepção, que é embasada no que ele já conhecia previamente. Sobre este conhecimento prévio em especial (essa observação vale para os que já tiveram contato com LEGO $^{\circ}$ na escola) a percepção do estudante para montar o protótipo na oficina é realmente a percepção que cada um traz consigo sobre as atividades com LEGO' que teve na escola. Buscando compreender as suas percepçóes, as professoras pesquisadoras buscaram informaçóes junto às escolas dos estudantes para compreender como eram realizados os procedimentos sobre as atividades com LEGO ${ }^{\circ}$.

Para sua surpresa, as escolas que os alunos frequentavam que tinham atividades com LEGO funcionavam todas da mesma forma. Quando as atividades eram oferecidas aos estudantes, as mesmas já vinham com um roteiro de montagem, sendo a função do estudante somente identificar as peças a serem encaixadas e realizar a montagem do protótipo conforme o esquema visual, previamente apresentado. Como nas nossas oficinas náo existia um roteiro de montagem, identificou-se que os estudantes que já trabalharam com LEGO $^{\circ}$ na escola estavam se sentindo perdidos, pois não tinham em mãos um roteiro de montagem. É entáo possível intuir que a montagem era realizada por eles de forma mecânica, sem espaço para a imaginação, a exploração, o erro e acerto. Dessa forma, surpreendentemente, a experiência prévia, na escola, não só não propiciou uma maior desenvoltura nas montagens, como até inibiu os estudantes, deixando-os inseguros por terem sidos expostos a situaçóes não controladas. Aqui pode ser evocado o terceiro princípio acima referido o princípio da desaprendizagem. Com o passar do tempo, as professoras pesquisadoras conseguiram estabelecer com esses estudantes uma relaçáo mais aberta e franca, relação essa que autorizou conselhos do tipo "deixe de lado ideias prontas, construa protótipos de acordo com tua imaginação, invente o que tiver vontade".

Dando seguimento às observaçóes recolhidas do diário de bordo, destacaremos a seguir o último nível de conhecimento prévio dos estudantes, aqueles que náo tiveram contato algum com $\mathrm{LEGO}^{\circ}$, nem mesmo na infância. Esses relatos só vieram a enriquecer nossas reflexôes e só foram possíveis graças à oferta da oficina a uma escola de periferia do município de Flores da Cunha. Nesse momento descreveremos brevemente o contexto social no qual a escola está inserida. Conforme observaçóes relatadas pela professora titular, os alunos desta escola encontram-se em uma situaçáo de vulnerabilidade social: para exemplificar, todos usam uniforme, mas somente porque a escola forneceu. Quando perguntados sobre terem tido, previamente, contato com o $\mathrm{LEGO}^{\circ}$, todos responderam que náo, nem mesmo na infância. Esta oficina iniciou da mesma forma que as demais, foi apresentada a proposta de construção do protótipo, suas dimensões finais e foram demonstradas algumas formas de montagem das estruturas básicas, após o que os estudantes foram convidados a montar os protótipos, deixando sua imaginação fluir.

O primeiro ponto que chamou a atenção na observação das professoras foi o deslumbramento dos estudantes com as peças, mas principalmente com as possibilidades de montagem, que com essa estrutura eles poderiam realizar as mais diversas montagens de protótipos. Tal encanto era tamanho que alguns, por vezes, 
se esqueciam do objetivo de montagem. Acredita-se que alguns teriam seguido por outros caminhos de montagem caso as professoras não estivessem observando atentamente as construçóes. O segundo ponto que diferenciou esta turma das demais foi a proposta de "enfeitar" o protótipo. Praticamente todos os grupos acrescentaram ao menos um elemento de ornamentaçáo, além da construção funcional do protótipo em si. Isso possibilitou evidenciar que os grupos construíram uma relação mais emocional com suas montagens. Mas o terceiro ponto de observação foi o que chamou mais atenção das professoras. Foi entregue aos grupos um motor para movimento do protótipo que, neste caso, era um carrinho. Os grupos não sabiam como conectar o motor e iniciou-se um diálogo entre os grupos, sem saber como surgiu esta ideia, todos os grupos apresentaram o motor somente sobreposto acima do carrinho, sem nenhuma conexão com o eixo. Esta observação deixou as professoras em choque, uma vez que tal situação não havia sido verificada em nenhuma das oficinas já realizadas. Isso porque esse era um conhecimento que, na percepção inicial das professoras, era básico e a relação entre a ligação de um motor com os eixos das rodas deveria ser intuitiva. Mais uma vez, uma concepção inicial se mostrou equivocada.

Ressaltamos aqui a riqueza nas observaçóes desta oficina: como nenhum dos grupos identificou a forma de conectar o motor, algum estudante provavelmente decidiu somente colocá-lo acima da estrutura do carrinho, sem ligação com os eixos e os demais grupos o seguiram na proposta. Relatamos nossa observação com os conhecimentos prévios, pois nenhum estudante da turma associou a construção do seu carrinho com a própria força de funcionamento de um carro. Outra observação que se fez é que o interesse deles em ornamentar seus carros era maior do que propriamente a montagem da estrutura para o seu funcionamento. Após a identificação desses fatos, as professoras fizeram uma analogia com um veículo de verdade indicando que o eixo do motor precisa estar conectado ao eixo das rodas para ocorrer a movimentaçáo do veículo. Ficou evidente o aprendizado através do erro no momento do funcionamento do carrinho, sendo que se observou o vislumbramento por parte dos estudantes quando seus protótipos se movimentaram segundo a lógica definida pela programação do controlador.

\section{Conclusáo}

O diário de bordo nas oficinas de robótica foi estruturado com a intenção, no início, de deixar registrados os diferentes acontecimentos percebidos pelas pesquisadoras no transcorrer das atividades. A intenção era a de tomá-los como base para um melhor preparo da oficina subsequente. Essa visáo das professoras pesquisadoras estava baseada nos conceitos de Paulo Freire (1996), que preconiza que o professor deve realizar uma reflexão crítica sobre a sua prática docente, relacionando num único conjunto a teoria e a prática. Não tínhamos, ao longo dos três primeiros anos de anotaçóes em diário de bordo, a pretensão de transformar essas observaçóes em uma pesquisa propriamente dita. Foi somente no quarto ano 
de atividades, quando nos deparamos com uma turma atípica, que nos demos conta do potencial reflexivo que tínhamos em mãos.

Ao descrevermos as percepçôes, não elencamos as categorias de estudantes considerando os conhecimentos prévios, pois conforme Ausubel (1980) o conhecimento prévio é essencialmente individual. Por esse motivo, consideraremos as categorias listadas a seguir como condiçôes prévias, como será explanado a seguir.

Categoria 1 - estudantes sem contato prévio com LEGO’, nem mesmo na infância; os estudantes que se encontram nesta categoria nunca tiveram contato com o brinquedo LEGO', sendo composta por participantes em vulnerabilidade social oriundos de uma escola de periferia.

Categoria 2 - estudantes que tiveram contato com LEGO ${ }^{\circ}$ na infância; nesta categoria se encontram a grande maioria dos participantes das oficinas de robótica.

Categoria 3 - estudantes que além de terem contato com LEGO $^{\circ}$ na infância, também tiveram contato na escola; os estudantes desta categoria são uma minoria que teve condiçóes de estudar em uma escola privada e tendo a oportunidade ainda de frequentar um curso de robótica extraclasse.

As categorias foram identificadas durante a realização das oficinas, através de diálogos informais com os estudantes e descritos no diário de bordo.

Quando do início das oficinas e apresentação das atividades, não se buscou classificar os estudantes quanto ao seu contato anterior com LEGO ${ }^{\circ}$. Estas verificaçôes foram surgindo em diálogos informais durante as atividades, após os quais, identificando o que denominamos de condiçóes prévias, foram percebidas certas semelhanças de comportamento de acordo com as mesmas.

Nos primeiros três anos de oficinas recebemos estudantes vinculados exclusivamente às categorias 2 e 3 . Dentre estas duas categorias as atividades propostas tinham um desenrolar contínuo, porém algumas percepçóes sobre os estudantes da categoria 3 eram menos favoráveis. Observando as categorias, se definiria que os estudantes da categoria 3 teriam uma melhor desenvoltura e facilidade na construção dos protótipos propostos. Porém, não foi o que ocorreu e houve uma inibição por parte dos estudantes em questionarem as professoras sobre a forma de realização das atividades que estavam em desenvolvimento. Esta inibição pareceu, na percepção das pesquisadoras, dever-se ao fato destes estudantes já terem participado de campeonatos ou mesmo atividades específicas de robótica e se sentirem envergonhados por não estarem desenvolvendo a tarefa de forma satisfatória, em outras palavras, por realmente estarem tendo dificuldades na montagem, o que pôde ser percebido pelas constantes desmontagens das estruturas já construídas, feitas por esses estudantes. Observando esta situação à luz de Moreira e Massini (2011), este estudante está desenvolvendo a atividade com base em sua realidade pregressa, quer dizer, nos cursos de robótica oferecidos nas escolas, as construçóes já vinham com orientaçóes pré-prontas, na qual o estudante realizava a atividade de forma mecânica, e, consequentemente, o recurso eventual à criatividade era sistematicamente desnecessário. 
Ainda segundo Moreira e Massini (2011), este estudante, ao montar e desmontar reiteradas vezes sua estrutura, estará aprendendo pelo erro, pois como nunca lhe foi propiciada autonomia para construir seus próprios protótipos utilizando conhecimentos prévios e deixando fluir a imaginaçáo ele precisa construir e desconstruir para compreender o processo no qual está envolvido. Do mesmo modo, com o passar do tempo, ele vai desaprendendo a construir de forma mecânica e reaprendendo a construir conforme a necessidade da estrutura e de acordo com o que a sua imaginação determinar.

Já na atividade trabalhada com os estudantes da categoria 1 o que não faltou foi motivação e criatividade. No início da oficina as professoras apresentaram apenas alguns exemplos sumários de montagem e deixaram as construçôes a critério de cada grupo. Como não houve uma investigação anterior sobre as condiçôes prévias destes estudantes, não ocorreu um pré-julgamento com relação à categoria. Contudo, se fosse de conhecimento das professoras que os estudantes pertenciam à categoria 1 , talvez tivessem apresentando mais formas de montagem e possivelmente náo esperariam um resultado táo satisfatório quanto o que foi observado. Segundo Paulo Freire (1979) o homem tem um ímpeto criador, e esse ímpeto pode ser verificado na construção dos carrinhos por parte destes alunos. Mesmo sem terem tido contato com o LEGO ${ }^{\circ}$ sua intuiçáo foi predominante na construçáo da estrutura, que, além de funcional ainda foi ornamentada - por todos os grupos. É possível apontar aqui indícios do que Paulo Freire (1979) denominou de educação desinibidora, educação essa que, ao situar-se no polo inverso da educação restritiva, torna-se mais autêntica e significativa.

Por não possuírem conhecimentos prévios de manuseio das estruturas, os estudantes desta categoria não conseguiram inicialmente colocar o carrinho para andar sozinho, pois não se deram conta de imediato que o eixo do motor precisava estar acoplado de alguma forma ao eixo das rodas para que houvesse a movimento através do controle. Neste caso foi necessária a intervenção das professoras orientando sobre esta questáo construtiva e demonstrando uma possibilidade de fazê-lo. A desconstruçáo e reconstrução do carrinho foi realizada de forma rápida, dada a habilidade já desenvolvida por eles no manuseio das peças. A euforia dos grupos quando o carrinho começou a se movimentar sozinho através do comando do controlador, foi algo digno de nota. A satisfação das professoras certamente náo foi menor, em ver a tarefa executada e ao reconhecer indícios da construçáo de novas aprendizagens significativas (AUSUBEL, 1980)

Com os estudantes da categoria 2 foi possível perceber também uma grande motivação e interesse na construção dos protótipos, semelhante ao percebido com os estudantes da categoria 1. O que se pode relatar de diferente tem relaçáo com a construção da estrutura de movimento, pois estes estudantes tinham noçáo de que havia a necessidade de comunicação entre os dois eixos, o do motor e o das rodas, porém também tiveram um pouco de dificuldade ao tentar realizar essa comunicação. Aqui também, ainda segundo Moreira e Massini (2011) eles estavam aprendendo com o erro, porque construíam conforme suas intuições, e desmontavam quando percebiam que náo funcionava, e montavam novamente 
de outra forma. E, conforme o tempo foi passando e as atividades avançando em nível de complexidade, observou-se que estas desmontagens, de protótipos que não condiziam com a necessidade, foram ficando mais raras, que já havia uma discussão entre o grupo e um planejamento antes da construção definitiva. É importante também destacar que a versão final de cada protótipo elaborado tinha a identidade do grupo, inclusive com sua ornamentação própria, o que certamente não ocorreria se fossem dadas previamente instruçóes explícitas sobre como deveria ser feita a montagem. Essas observações, na percepção das pesquisadoras, revelam indícios de aprendizagem significativa no que diz respeito aos modos de construçáo dos protótipos com LEGO ${ }^{\circ}$.

Desse modo podemos finalizar concluindo que, mesmo em atividades extraclasse, há sim a necessidade de identificar as condiçôes prévias de cada estudante. Entretanto, o professor deve fazer esta busca com o intuito não de pré-julgar, mas sim de redesenhar o que tinha previsto, com base nessas condiçóes prévias, sempre intentado propiciar aos estudantes, no maior grau possível, um ambiente acolhedor e propício à emergência da criatividade.

\section{Referências:}

AUSUBEL, David P., NOVAK, Joseph D., HANESIAN, Helen. Psicologia

Educacional. 2.ed. Rio de Janeiro: Interamericana, 1980.

FREIRE, Paulo. Educaçáo e Mudança. Tradução de Moacir Gadotti e Lilian Lopes Martin. Rio de Janeiro: Paz e Terra, 1979.

Pedagogia do oprimido. Rio de Janeiro: Paz e Terra, 36a edição, 1987.

. Pedagogia da autonomia: saberes necessários à prática educativa. São

Paulo: Paz e Terra, 30a ediçáo, 1996.

MORALES, A.C.; GIACOMELLI, P. Trabalhando conceitos de física com estruturas de LEGO: um relato de experiência. Anais do XLVII Congresso Brasileiro de Educaçáo em Engenharia. Fortaleza, Ceará, ABENGE, 2019.

MOREIRA, M. A.; MASINI, E. F. S. Aprendizagem Significativa. A Teoria de David Ausubel. São Paulo: Centauro, 2001- 2011 (2a. Reimpressão). 